\title{
El uso persuasivo de los términos politicos como origen de controversias terminológicas
}

\author{
The Persuasive Use of Political Terms \\ as Source of Terminological Controversies
}

José Antonio Sendín Mateos

Universidad de Salamanca jasendin@usal.es

DOI: http://doi.org/10.15366/bp2019.20.007

Bajo Palabra. II Época. No20. Pgs: 125-142 
Este trabajo ha sido realizado en el marco del proyecto de investigación

"El desván de la razón: cultivo de las pasiones, identidades éticas y sociedades digitales": PAIDESOC (FFI2017-82535-P).

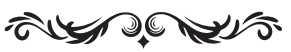

\section{Resumen}

El significado emotivo que acompaña a muchos términos políticos ha dado lugar, en el ámbito de la teoría política, a numerosos desacuerdos sobre el uso de los mismos. Para ilustrar esas controversias me referiré a una discusión de Hans Kelsen con Lenin -sobre el concepto de democracia- y a otra con Eric Voegelin, en torno a la noción de representación política. Para identificar de qué tipo de desacuerdos se trata, utilizaré una clasificación de controversias terminológicas que proporciona Genaro Carrió.

Palabras Clave: definiciones persuasivas, controversias terminológicas, términos politicos, democracia, representación política.

\section{Abstract}

The emotional meaning that is usually associated with lots of political terms has led, in the frame of political theory, to many disagreements about their use. To illustrate these controversies I will refer to a discussion of Hans Kelsen with Lenin -about the concept of democracy- and another one with Eric Voegelin, that concerns the notion of political representation. To identify what kind of disagreements haven arisen, I will use a classification of terminological controversies provided by Genaro Carrió.

Keywords: persuasive definitions, terminological controversies, political terms, democra$c y$, political representation. 


\section{Las definiciones "persuasivas" de los términos políticos: una consecuencia de su propensión a "cargarse" con un significado emotivo}

EN ESTE TRABAJo EXAMINARÉ DE QUÉ MANERA la carga emotiva que suele acompañar a un gran número de términos políticos puede desembocar en diferentes tipos de disputas terminológicas entre quienes representan posiciones filosófico-políticas diversas. Para ejemplificar esas controversias me referiré a dos discusiones en las que Hans Kelsen es protagonista: una con Lenin sobre el concepto de democracia y otra con Eric Voegelin sobre la noción de representación política.

Es bien conocido que nuestro vocabulario político está repleto de términos que combinan un significado descriptivo y un significado emotivo. Al tener un significado descriptivo, siguiendo a Charles Stevenson, esos términos suministran información y se caracterizan por su disposición a afectar a la cognición ${ }^{1}$; y al mismo tiempo se "cargan" con un significado emotivo, buscando inducir en el oyente determinadas actitudes que, dependiendo de la realidad que designen, pueden ser favorables o desfavorables, de aprobación o desaprobación. Un ejemplo muy obvio de una palabra que forma parte del vocabulario político y tiene una carga emotiva desfavorable es "dictador". En cambio, la palabra "democracia" tiene un significado emotivo positivo, debido, en parte, a que su significado descriptivo se refiere a algo que para la mayoría de los ciudadanos resulta valioso, a saber: una forma de organización política que es apreciada en las sociedades actuales ${ }^{2}$. Eso hace que esta palabra se "cargue" con un significado emotivo claramente favorable.

La mención de la palabra "democracia" es muy pertinente porque seguramente es uno de los términos del vocabulario político que más se ha prestado a la estipulación de definiciones. Estas pueden ser muy diferentes dependiendo de la ideología de cada uno o del punto de vista filosófico-político de quien estipula la definición. Un rasgo de los términos políticos -y en general de los términos susceptibles de adquirir un significado emotivo- es que su significado descriptivo a menudo es vago y no está completamente determinado por las reglas lingüísticas ${ }^{3}$. La forma de mitigar el efecto de esa vaguedad es estipulando reglas para su uso, lo cual se logra a través de defini-

\footnotetext{
${ }^{1}$ Stevenson, Ch., Ethics and Language, New Haven and London, Yale University Press, 1944, pp. 67 y 70.

2 Ibid., p. 72.

${ }^{3}$ Ibid., pp. 71 y $141-142$.
} 
ciones estipulativas. Frente a las definiciones léxicas-como las que se contienen en los diccionarios-, que se limitan a encontrar y explicar cuáles son las reglas de uso de un término dentro de una determinada comunidad de hablantes ${ }^{4}$, las definiciones estipulativas fijan ellas mismas esas reglas, precisando cuál es el significado de un término en el contexto discursivo en el que suele utilizarse. En concreto, en el ámbito de la ciencia es frecuente servirse de definiciones estipulativas para delimitar el significado de los términos científicos o para introducir otros nuevos ${ }^{5}$. Pero también lo es en la teoría política, donde se han definido prolijamente términos como "democracia", "representación", "soberanía", "ciudadanía” o "república", entre otros.

Ahora bien, cuando se estipulan las reglas de uso de términos que son susceptibles de producir un efecto emotivo ( $v \cdot g r$ los términos éticos y los términos políticos) y que van a ser utilizados en un contexto teórico (o teórico-político), es frecuente recurrir a las definiciones emotivas o retóricas, o según la denominación de Stevenson, "definiciones persuasivas". Estas definiciones estipulan un nuevo significado conceptual a palabras que nos son familiares sin modificar sustancialmente su significado emotivo, buscando influir sobre los intereses de las personas ${ }^{6}$. En definitiva, estipulan un nuevo significado apoderándose del sentido emotivo de esas palabras, y redefiniéndolas con el objetivo de inducir actitudes de aprobación o desaprobación que redirijan los intereses individuales del oyente. De ahí que esas definiciones se empleen a menudo con fines de propaganda política.

Dicho esto, en mi trabajo examinaré un caso particular, aunque no por ello menos paradigmático, de cierta controversia terminológica que se ha dado tradicionalmente en la teoría política en torno a las nociones de "democracia" y de "representación política". Ambos son términos políticos susceptibles de definirse persuasivamente. Para ilustrarla, explicaré la forma como un firme defensor de la democracia, como sin duda fue Hans Kelsen, confronta, por un lado, su visión sobre ese concepto con el ideal de democracia característico de Lenin y la teoría política bolchevique, que en el fondo no representa otra cosa que la dictadura del proletariado; y por otro lado, aunque en estrecha conexión con este asunto, una interesante pero escasamente conocida polémica que giró en torno al concepto de representación política y que protagonizó el propio Kelsen junto a uno de sus antiguos discípulos: Eric Voegelin. Al final de mi exposición trataré de identificar, apoyándome en la aguda visión del filósofo del derecho argentino Genaro Carrió, ante qué tipos de disputas terminológicas nos encontramos.

\footnotetext{
${ }^{4}$ Rodilla, M. A., Teoría del Derecho, Salamanca, Ratio Legis, 2013, p. 26.

5 Guiboug, R.; Ghigliani, A.; Guarinoni, R.; Introducción al conocimiento jurídico, Buenos Aires, Astrea, 1973, p. 62.

${ }^{6}$ Stevenson, Ch., "Persuasive Definitions", Facts and Values. Studies in Ethical Analysis, Westport (Connecticut), Greenwood Press, 1975, p. 32.
} 


\section{Una aproximación a la visión kelseniana sobre la democracia y la representación política}

Puesto que Kelsen es el punto de partida, un paso previo a la explicación de esas controversias terminológicas es realizar una breve caracterización de su concepción de la democracia, con el objetivo de fijar unas pocas coordenadas. Con ello no pretendo una descripción exhaustiva de su posición en defensa de la democracia, sino únicamente introducir la cuestión que luego desarrollaré.

El grueso del pensamiento democrático kelseniano se desarrolló principalmente en el periodo comprendido entre 1920 y 1930. Por entonces la democracia se concebía comúnmente en términos "formales", anteponiendo los aspectos procedimentales - pues se contemplaba como un método para generar, con la participación del cuerpo electoral, las normas legislativas por las que se rige la sociedad-a los aspectos sustantivos, ( $v . g r$. los derechos fundamentales) que ha de salvaguardar todo régimen político para que se pueda considerar democrático. En esta perspectiva hay que reconocer a Anna Pintore ${ }^{7}$ el mérito de, por así decirlo, haber "radiografiado" la teoría kelseniana de la democracia, presentándola como una concepción que, aunque prima facie es "procedimental" -pues entiende que la democracia es, ante todo, un método para producir normas generales-, admite a su vez que ese concepto se puede enriquecer con contenidos adicionales. Esto le lleva a diferenciar entre definiciones "mínimas" y definiciones "más que mínimas" de la democracia. Las primeras se circunscriben al núcleo procedimental de la democracia, mientras que las segundas cualifican ese núcleo añadiendo nuevos elementos ${ }^{8}$. Aunque Pintore no llega a cuestionarse si esas definiciones se refieren a una supuesta "esencia" de la democracia, o si, en cambio, tratan de estipular reglas de uso para ese término, si damos por buena su clasificación, parece claro que el concepto de Kelsen pertenece al segundo grupo: es propio de una concepción de la democracia "más que mínima”, que grosso modo puede adjetivarse como sigue:

1. Es una democracia "formal" o "procedimental", pues como he indicado antes, se contempla como un método para la creación de las normas del sistema jurídico, que consiste en aplicar en el proceso legislativo un procedimiento de decisión por mayoría. Esto supone admitir que los participantes en ese proceso gozan de la misma capacidad de influir en la formación de la voluntad colectiva.

\footnotetext{
7 Pintore, A., "Democracia sin derechos. En torno al Kelsen democrático", DOXA, 23, 2000, pp. 127 y ss.

${ }^{8}$ Ibid., p. 133.
} 
2. Es una democracia "representativa" o "indirecta", que se apoya en dos pilares: el parlamento como órgano representativo y los partidos políticos como el instrumento para ejercer esa representación.

3. Atendiendo a la forma como se articula el procedimiento legislativo, es una democracia "deliberativa", que contempla el compromiso y el intercambio racional de argumentos como el motor de avance de la técnica legislativa.

4. Los condicionantes sustantivos que están implicados en su idea de democracia $-v$. gr. los derechos fundamentales- hacen pensar en una concepción "liberal", aunque su liberalismo es sui generis, por dos motivos: (i) porque se circunscribe al ámbito político y no al económico, y entiende que la democracia como sistema político puede ser compatible con una economía capitalista y con una socialista, y (ii) porque se aparta del individualismo que caracteriza a algunas versiones del liberalismo y defiende la intervención del Estado para garantizar cierto bienestar.

5. Por último, Kelsen desarrolló por separado una teoría de la democracia y una teoría de la constitución, aunque sin llegar a integrarlas sistemáticamente en una teoría de la democracia "constitucional". Sin embargo, esto no quiere decir que en su concepto de democracia no existan rasgos de una concepción de democracia constitucional, sino que cabe mencionar al menos tres: (i) el reconocimiento del principio de separación de poderes, a pesar de la actitud titubeante de Kelsen hacia el mismo; (ii) en conexión con la tradición liberal, la protección de los derechos políticos de las minorías y la exigencia de evitar posibles abusos por parte de la mayoría; y (iii) la creación de una jurisdicción constitucional como medio para proteger esos derechos a través de un procedimiento de oficio diseńado con ese fin.

En este momento no me detendré a explicar detalladamente estos rasgos, sino que me remitiré a un trabajo anterior ${ }^{9}$. Sin embargo, para comprender mejor -sobre todo- la polémica entre Kelsen y Voegelin, conviene poner el foco en la combinación que se da en la concepción kelseniana de la democracia entre el componente representativo y el componente liberal. Por un lado, como consecuencia de adscribirse a un ideario liberal-democrático, Kelsen opina que la libertad es el valor que toda democracia debe aspirar a realizar en primer término; pero, por otro lado, esa

${ }^{9}$ Sendín, J. A., La filosofía moral de Hans Kelsen, Madrid, Marcial Pons, 2017, pp. 285 y ss. 
aspiración solo se puede satisfacer a través del ejercicio de la representación política, es decir, como resultado de un proceso electoral en el que los votantes participan en pie de igualdad. En su opinión, la idea de una representación igual es la seña de identidad de la democracia "formal" o "burguesa" frente a la democracia "social" o "proletaria", que está interesada no solo en lograr una representación política igual, sino también una distribución lo más equitativa posible de los bienes y ventajas sociales ${ }^{10}$. A continuación daré cuenta de algunos rasgos que, a mi modo de ver, caracterizan significativamente la concepción de la democracia de Kelsen como (a) una democracia representativa y (b) una democracia liberal.

a) Kelsen defiende una democracia representativa que se apoya en el parlamento como órgano representativo y en los partidos políticos como el cauce para articular esa representación. El carácter representativo de la democracia se expresa en su definición del parlamentarismo, que él identifica con la "la formación de la voluntad normativa del Estado por un órgano colegiado que decide por mayoría y que es elegido por el pueblo por sufragio universal e igual, es decir, democráticamente" ${ }^{11}$.

La creación de normas generales, el desarrollo del sistema jurídico por medio del procedimiento legislativo, tiene lugar en el parlamento, aplicando la regla de la mayoría y buscando alcanzar compromisos entre los distintos grupos parlamentarios en casos en los que el asentimiento necesario para adoptar una decisión no se pueda obtener con las solas fuerzas de un único grupo. Es así como se desarrollan los procesos políticos en las sociedades modernas, cuya complejidad creciente prácticamente imposibilita aplicar un sistema de democracia directa ${ }^{12}$. A pesar de ello, Kelsen entiende que la aspiración de que el pueblo, constituido como cuerpo legislativo, trate de convertir su voluntad en ley, no se puede eliminar del pensamiento democrático. Seguramente por esa razón pervive en la conciencia colectiva como un ideal que, aunque es inalcanzable, predetermina una tendencia de los regímenes parlamentarios hacia la maximización de la libertad política, incorporando medidas como la iniciativa popular y el referéndum. Con esto se pretende dar un mayor protagonismo al cuerpo electoral en la producción legislativa ${ }^{13}$.

\footnotetext{
${ }_{10}$ Kelsen, H., Esencia y valor de la democracia, Oviedo, KRK Editores, 2006, p. 211.

11 Ibid., p. 92.

12 Ibid., p. 87; Kelsen, H., Allgemeine Staatslehre, Berlin, Julius Springer, 1925, p. 536; "Vom Wesen und Wert der Demokratie” (1. Auflage), Verteidigung der Demokratie, Tübingen, Mohr Siebeck, 2006, pp. 11 y 14.

${ }^{13}$ Kelsen, H., Allgemeine Staatslehre, op. cit., pp. 356-357; Esencia y valor de la democracia, op. cit., pp. 114-115; "El problema del parlamentarismo", Escritos sobre la democracia y el socialismo, Madrid, Debate, 1988. p. 89.
} 
La visión de Kelsen del parlamento como órgano de representación del pueblo es quizá el rasgo más significativo de su idea de la democracia representativa, pero no es el único. Al mismo tiempo concurren otros elementos que en este momento apenas puedo limitarme a mencionar, pero sin los cuales su concepción no podría explicarse:

1. La democracia representativa descansa sobre los partidos políticos. Por eso el Estado democrático es para Kelsen un Estado de partidos ${ }^{14}$, que son el instrumento que permite expresar el pluralismo social. Por esta razón los partidos políticos se insertan en los textos constitucionales ${ }^{15}$. Ahora bien, Kelsen no ignora el descrédito creciente de los partidos políticos en la década de 1920. A su juicio, la desconfianza hacia los mismos explicaría, en parte, los ataques de los que por entonces era objeto la democracia.

2. El rechazo del mandato imperativo ${ }^{16}$, pues Kelsen opina que era un vestigio de la vieja monarquía estamental. Aunque una parte del pueblo demandaba restablecer el mandato imperativo para dirigir instrucciones vinculantes a sus representantes, Kelsen replica que en una democracia representativa moderna los diputados no deberían estar vinculados por esas instrucciones ${ }^{17}$. Se sobreentiende, por tanto, que prefiere el mandato representativo, lo cual nos lleva al siguiente punto.

3. El distanciamiento del dogma de la soberanía popular y su sustitución por la idea de representatividad. Si los diputados no pueden recibir instrucciones vinculantes de los electores, tienen vía libre para realizar sus tareas con independencia. Esto implica alejarse del ideal rusoniano de la soberanía popular ${ }^{18}$. Aunque para Kelsen el monopolio de la potestad legislativa recae sobre el parlamento, concede un lugar central al pueblo, a pesar de que su intervención en el proceso legislativo queda limitada a la elección del parlamento ${ }^{19}$.

${ }_{14}$ Kelsen, H., Esencia y valor de la democracia, op. cit., p. 73.

15 Ibid., p. 71.

16 Ibid., p. 97; Kelsen, H., "El problema del parlamentarismo", op. cit., p. 88; "Vom Wesen und Wert der Demokratie", op. cit., p. 11.

${ }_{17}$ Kelsen, H., "Vom Wesen und Wert der Demokratie", op. cit., p. 11.

${ }^{18}$ A Kelsen ese ideal le parece una ficción, e incluso llega a decir que "la teoría de la soberanía popular es una máscara totémica, aunque muy refinada y espiritualizada". Esencia y valor de la democracia, op. cit., p. 199.

${ }_{19}$ Kelsen, H., Allgemeine Staatslehre, op. cit., p. 315. 
4. La defensa de un sistema electoral proporcional, que para Kelsen favorece que la composición del parlamento sea un reflejo del pluralismo social. Quienes se oponen a ese sistema objetan que propicia la formación de grupos parlamentarios pequeños. Lejos de ver en esto una desventaja, Kelsen replica que solo significa la necesidad de formar coaliciones de partidos para alcanzar mayorías estables, lo que supone un avance para la democracia ${ }^{20}$. También defiende las listas cerradas, porque si los candidatos obtienen su mandato por su pertenencia a un partido, es razonable que lo pierdan si dejan de formar parte de él ${ }^{21}$.

5. El rechazo de la representación profesional. Para Kelsen la propuesta de crear parlamentos integrados por grupos profesionales es una amenaza para la democracia, pues implica suprimir el sistema representativo y sustituir el parlamento por un órgano estamental ${ }^{22}$ que no representa el pueblo, sino a grupos o gremios profesionales. Cosa distinta es que un parlamento necesite del asesoramiento de expertos para legislar sobre materias que exigen especialización técnica. En esos casos se pueden formar comisiones especializadas que son coordinadas por el pleno. Esas comisiones no suponen un peligro para la democracia, sino que contribuyen a reforzarla, pues ayudan a orientar el proceso de formación de la voluntad colectiva en la dirección adecuada ${ }^{23}$.

6. Una propuesta de reforma del parlamentarismo, a fin de potenciar el control de los electores sobre los actos de sus representantes. Para que el control sea eficaz habría que eliminar o restringir severamente el privilegio de la inmunidad parlamentaria, que para Kelsen es un anacronismo ${ }^{24}$. También propone medidas dirigidas a aproximarse al ideal de la participación directa, concediendo al pueblo un mayor protagonismo en el desarrollo de las funciones legislativas. Entre esos mecanismos destacan el referéndum legislativo (o constitucional) y la iniciativa popular ${ }^{25}$.

${ }^{20}$ Kelsen, H., Esencia y valor de la democracia, op. cit., pp. 155-156; "El problema del parlamentarismo", op. cit., p. 101.

${ }^{21}$ Kelsen explica que la Constitución Soviética va más lejos en esta previsión, pues los miembros de los soviets pueden ser sustituidos en cualquier momento por los electores. Esto explicaría, en parte, por qué la Constitución Soviética se ha ganado la simpatía de tantos trabajadores en el extranjero. Esencia y valor de la democracia, op. cit., pp. 122-123.

22 Ibid., p. 134.

23 Ibid., pp. 125-126.

${ }_{24}$ Ibid., p. 118; Kelsen, H., "El problema del parlamentarismo", op. cit., p. 91.

25 Kelsen, H., Allgemeine Staatslere, op. cit., pp. 356-357; Esencia y valor de la democracia, op. cit., p. 114; "El problema del parlamentarismo", op. cit., p. 89. 
b) El liberalismo de Kelsen se caracteriza ante todo porque defiende la necesidad de reconocer y garantizar unos derechos subjetivos cuya titularidad pertenece a todos los ciudadanos, que obtienen protección frente al Estado y otros individuos. Este rasgo se observa, por ejemplo, en su apasionada defensa de la Constitución de la República de Weimar, que él califica "como la constitución más libre que un pueblo haya producido jamás" y "la constitución más democrática del mundo" ${ }^{26}$, pues a su juicio ninguna otra constitución ha conseguido realizar, de forma tan satisfactoria, el principio matriz de la única democracia verdadera -que para él es la democracia liberal-, a saber: el principio de libertad y de autodeterminación individual ${ }^{27}$. Además, esa constitución reconoce un gran número de derechos y libertades, de ahí su enorme valor.

Como teórico liberal, Kelsen está muy interesado en la protección de los derechos políticos de las minorías (étnicas, religiosas, etc.). En particular, le preocupan las que pueden influir en los procesos legislativos, y trata de evitar su aplastamiento o, mutatis mutandis, la situación que la teoría política liberal tradicional ha denominado "tiranía de la mayoría" ${ }^{28}$. Esto le lleva a seguir la senda trazada por su maestro Georg Jellinek, que defendía la necesidad de establecer límites a la voluntad de la mayoría parlamentaria y de crear las condiciones para evitar que se pisoteen en el órgano legislativo los derechos de las minorías. Y al hacerlo, Kelsen se considera continuador de la tradición liberal que está representada por pensadores como Benjamin Constant, John Stuart Mill o Alexis de Tocqueville ${ }^{29}$.

La protección de los derechos políticos de las minorías juega un importante papel en la teoría kelseniana de la democracia. Así opina García Amado, para quien el vínculo que se establece en esa concepción entre democracia y liberalismo no es accidental ni coyuntural, sino determinante ${ }^{30}$.

${ }^{26}$ Kelsen, H., "Verteidigung der Demokratie", Verteidigung der Demokratie, Tübingen, Mohr Siebeck, 2006, p. 229.

27 Ibid., p. 231.

${ }^{28}$ Kelsen suele hablar del "imperio" (Herrschaft) de la mayoría. Allgemeine Staatslehre, op. cit., pp. 324 y 370; "El problema del parlamentarismo", op. cit., p. 91; "Zur Soziologie der Demokratie", Die Wiener Rechtstheoretische Schule. Schriften von Hans Kelsen, Adolf Merkl, Alfred Verdross, 2, Wien, Europa Verlag, 1968, p. 1739.

${ }^{29}$ Lagi, S., El pensamiento politico de Hans Kelsen (1911-1920). Los orígenes de "De la esencia y valor de la democracia", Madrid, Biblioteca Nueva, 2007, pp. 68 y ss.

${ }^{30}$ García Amado, J. A.; Hans Kelsen y la norma fundamental, Madrid, Marcial Pons, 1996, p. 196. 


\section{El desacuerdo terminológico sobre los conceptos de democracia y representación política}

UNA VEZ EXPLICADO EL PESO que tienen en la teoría kelseniana de la democracia el elemento representativo y el elemento liberal, puedo presentar ya las dos controversias terminológicas que vengo mencionando. Una primera disputa se refiere al concepto de democracia. Este es uno de los términos del vocabulario político que suele utilizarse con una pretensión propagandística encubierta, como consecuencia del significado emotivo que generalmente se asocia a él. Tanto es así que incluso regímenes políticos diversos, cuyo punto en común es su distanciamiento de lo que comúnmente entendemos que es una democracia, han afirmado no solo ser democráticos, sino representar la democracia "verdadera". Tal fue el caso de los regímenes comunistas, que se autocalificaban como "democracias populares" 31 .

Kelsen censuró este abuso terminológico refiriéndose a él como una "perversión conceptual" 32 que atribuye a Lenin y a la teoría política bolchevique, que identificaban como democracia la dictadura del proletariado. Recuerda que según Marx y Engels el proletariado, que estaba unido por una conciencia de clase muy fuerte, representaba la abrumadora mayoría del pueblo, lo que permitiría establecer el socialismo por medios democráticos, sin que hubiera necesidad de recurrir a la revolución. En cambio, Lenin opina que la vía revolucionaria era la única que permitiría realizar el socialismo. Según él, una vez se ha alcanzado esta etapa, cuando el proletariado se convierte en la clase social dominante, la forma del Estado puede definirse como una democracia "completa" o una "inmensa expansión de la democracia" ${ }^{33}$, pues es una democracia para los pobres, para la gran mayoría del pueblo, y no para los ricos. Kelsen explica que aunque Lenin trató de aferrarse al ideal democrático una vez transcurrida la etapa revolucionaria, su esfuerzo fue vano, pues esa "inmensa expansión de la democracia" de la que él hablaba significó todo lo contrario. El bolchevismo se sirvió de un concepto de democracia que había sido conscientemente adulterado con el fin de ocultar la realidad de la dictadura del partido comunista ${ }^{34}$.

Pasando a la segunda controversia anunciada, Kelsen opina que una adulteración muy parecida fue la que llevó a cabo Eric Voegelin, aunque en esta ocasión no sobre

\footnotetext{
31 Rodilla, M. A., Teoría del Derecho, op. cit., p. 23.

32 Kelsen, H., "Los fundamentos de la democracia", Escritos sobre la democracia y el socialismo, Madrid, Debate, 1988. p. 214.

33 Ibid., p. 213.

${ }^{34}$ Kelsen, H., "La teoría política del bolchevismo. Un análisis crítico", Escritos sobre la democracia y el socialismo, Madrid, Debate, 1988, pp. 188 y 192.
} 
el concepto de democracia, sino sobre la noción de representación política. Este profesor alemán, que se doctoró en Derecho en la Universidad de Viena bajo la supervisión de Kelsen, se enfrentó a su antiguo maestro en una interesante discusión. En su libro The New Science of Politics. An Introduction (1952) Voegelin proponía un "nuevo" modelo de representación que se alejaba del paradigma liberal y diferenciaba una representación "elemental" y una representación "existencial". La primera se asocia con la democracia que denominamos "representativa". Él también se refiere a ella como representación "constitucional", dado que es organizada en las constituciones democráticas ${ }^{35}$. Voegelin rechaza ese concepto, porque opina que es una representación meramente formal y tiene un "escaso valor cognitivo" ${ }^{36}$. Con esa afirmación quiere expresar que la representación elemental apenas abarca una pequeña parte del complejo fenómeno de la representación política, y no permite explicarlo en toda su extensión, pues en su opinión un gobierno puede ser representativo de la sociedad en su conjunto incluso si no ha sido elegido por medios democráticos.

Para Voegelin el concepto "elemental" de representación ha de ser sustituido por otro "existencial", según el cual representan al Estado todos los individuos que actúan como órganos de la comunidad política al desempeñar funciones atribuidas por el orden social, independientemente de si el procedimiento que se utiliza para su designación es democrático o no. Es más, él sostiene que un sistema político puede ser representativo incluso cuando no se permite la libre formación de partidos políticos, o cuando existe un único partido ${ }^{37}$. Seguramente el mejor ejemplo de aplicación de un modelo existencial de representación es el régimen soviético, porque "no puede haber ninguna duda de que el gobierno soviético representa a la sociedad soviética como sociedad política apta para actuar en la historia" ${ }^{38}$. Para justificar esa afirmación, alega que los actos legislativos y administrativos del gobierno soviético "son eficaces en el plano interno en el sentido de que el pueblo obedece las disposiciones gubernamentales" ${ }^{39}$. El cumplimiento de esas disposiciones está asegurado, pues "el gobierno soviético puede operar con eficacia una gigantesca

${ }^{35}$ Kelsen, H., ¿Una nueva ciencia de la política? Réplica a Eric Voegelin, Buenos Aires, Katz Editores, 2006, p. 80. Kelsen replica que una representación no democrática también ha de ser establecida a través de un texto constitucional.

36 Kelsen, H., "Los fundamentos de la democracia”, op. cit., p. 218; ¿Una nueva ciencia de la política? Réplica a Eric Voegelin, op. cit., p. 82.

${ }^{37}$ Kelsen, H., "Los fundamentos de la democracia”, op. cit., p. 219; ¿Una nueva ciencia de la política? Réplica a Eric Voegelin, op. cit., p. 84.

38 Voegelin, E., La nueva ciencia de la política. Una introducción, Buenos Aires, Katz Editores, 2006, p. 51.

39 Ídem. 
maquinaria militar que se alimenta de los recursos humanos y materiales de la sociedad soviética" ${ }^{40}$.

Es obvio que estas ideas quedan muy alejadas de la noción de representación que maneja Kelsen. Voegelin entiende ese concepto como el control efectivo que ejerce el gobierno soviético sobre su pueblo ${ }^{41}$. Kelsen explica que Voegelin tiene que reconocer que "el gobernante representativo de una sociedad articulada no puede representarla en su conjunto sin tener algún tipo de relación con los demás miembros de la sociedad" ${ }^{2}$. Por "los demás miembros de la sociedad" solo se puede entender el pueblo, de manera que el gobierno soviético, aunque no es democrático, representa al pueblo soviético en sentido "existencial", pues ejerce un control efectivo sobre él. Voegelin no extrae esta conclusión explícitamente, pero para Kelsen es obvio que está implícita en su teoría de la representación ${ }^{43}$. En cambio, un demócrata militante como él no puede admitir como "representativo" un sistema que prohíbe la libre formación de partidos políticos, o en el que no existe más que un partido, pues ello significaría una tergiversación del concepto de representación política. En el lenguaje de Stevenson diríamos que se está recurriendo a una definición persuasiva. Kelsen es muy elocuente al manifestar que la tendencia a perpetrar esta burda metamorfosis conceptual es un rasgo común de las ideologías que dan sustento a regímenes antidemocráticos, como el nacionalsocialismo, el fascismo o el bolchevismo ${ }^{44}$.

\section{Una clasificación de las controversias terminológicas sobre términos políticos}

ESTAS CONTROVERSIAS TERMINOLÓGiCAS en las que se ve involucrado Kelsen muestran que el recurso a las definiciones persuasivas es cosa frecuente en la teoría política, y dan lugar a desacuerdos que, como ahora explicaré, presentan características similares, lo que permite agruparlos por categorías. A continuación trataré de iden-

\footnotetext{
40 Ídem.

${ }^{41}$ Kelsen explica que para Voegelin el instrumento de ese control es el ordenamiento jurídico estatal. De hecho, la eficacia de la que habla Voegelin no es la eficacia del órgano en la realización de sus funciones, sino que ha de interpretarse como la eficacia de las normas que crea y aplica ese órgano. En consecuencia, un gobierno es eficaz cuando son eficaces las normas que aprueba. Véase Kelsen, H., "Los fundamentos de la democracia", op. cit., p. 221; ¿Una nueva ciencia de la politica? Réplica a Eric Voegelin, op. cit., p. 90.

42 Voegelin, E., La nueva ciencia de la política. Una introducción, op. cit., p. 73.

${ }^{43}$ Kelsen, H., "Los fundamentos de la democracia”, op. cit., p. 224; ¿Una nueva ciencia de la política? Réplica a Eric Voegelin, op. cit., p. 95.

${ }^{44}$ Kelsen, H., "Los fundamentos de la democracia”, op. cit., p. 219; ¿Una nueva ciencia de la política? Réplica a Eric Voegelin, op. cit., p. 85.
} 
tificar de qué tipo son las dos controversias que he presentado. Para ello me serviré de una clasificación de Genaro Carrió, que aunque en principio está pensada para catalogar desacuerdos en el uso de los términos jurídicos, también se puede utilizar para dar cuenta de controversias sobre el significado de términos pertenecientes al vocabulario político o teórico-político. El propio Carrió insiste en este punto, y aclara que las controversias terminológicas que él pretende clasificar no afectan solo a los dogmáticos del derecho, sino también a los teóricos del derecho político y a los filósofos del derecho ${ }^{45}$.

1. Opino que en ambas polémicas de Kelsen con Lenin y Voegelin estamos ante las que Carrió identifica como "controversias generadas por un desacuerdo valorativo encubierto" 46 , que suelen producirse cuando están implicados términos susceptibles de cumplir una función emotiva, generalmente en el ámbito de la teoría jurídica o la teoría política. Este es el terreno idóneo para el uso de definiciones persuasivas ${ }^{47}$. En las dos disputas a las que me he referido están implicados conceptos de teoría política. Aunque tienen un obvio significado descriptivo, ambos destacan por su propensión a "cargarse" con un sentido emotivo. Si Stevenson está en lo cierto, "democracia" es una palabra de este tipo; y por extensión, a mi modo de ver también lo es la noción de "representación política" tal como la entiende Voegelin, especialmente en su variante de "representación existencial".

Seguramente el rasgo que permite catalogar esos desacuerdos como controversias valorativas, y que Carrió señala con lucidez, es que cuando estas se suscitan en torno a palabras como "democracia" suele apreciarse una propensión a ofrecer una "definición real" del concepto, es decir, no tanto a estipular un nuevo significado del mismo como a desvelar su "verdadera" esencia ${ }^{48}$. Esta tendencia se observa en la forma como Lenin se aproxima al concepto de democracia, que él identifica con la dictadura del proletariado. Esta sería la única democracia "verdadera", con lo que parece haber dado con la esencia misma de la democracia, frente a la impostura que representa la democracia burguesa. Este es un ejemplo muy obvio de una definición persuasiva, en la que la carga emotiva del término oscurece su

\footnotetext{
${ }_{45}$ Carrió, G., Notas sobre derecho y lenguaje, Buenos Aires, Abeledo-Perrot, 1973, p. 63.

${ }^{46}$ Ibid., pp. 77 y ss.

${ }^{47}$ Ibid., p. 77.

${ }^{48}$ Ídem.
} 
significado descriptivo. Esto mismo se podría objetar respecto de la noción voegeliniana de la "representación existencial", que desplaza el concepto "elemental" que se corresponde con la representación liberal-democrática. Él rechaza ese concepto porque es "meramente formal" -calificación que en su contexto tiene un evidente sesgo peyorativo- y por su "escaso valor cognitivo", pues no permite explicar en su totalidad el complejo fenómeno de la representación.

Por cierto, aunque no lo he mencionado, el propio Kelsen tampoco se ve libre de ese reproche, pues cuando expresa su preferencia por la idea de la democracia liberal, se puede inferir que él considera que ese concepto es el único verdadero. Baste indicar que el título de su escrito más conocido sobre la democracia, donde plasma como en ningún otro lugar su visión sobre ese sistema político, es Vom Wesen und Wert der Demokratie (Esencia y valor de la democracia).

2. En segundo lugar, para Carrió los desacuerdos que se apoyan en definiciones persuasivas también se caracterizan porque, al tratar de desvelar la esencia verdadera de un concepto, tienden a cubrirse con el ropaje de descripciones, dando lugar a un tipo de disputas que parecen versar sobre hechos y que él identifica como "seudo-desacuerdos de hecho sobre proposiciones analíticas" ${ }^{49}$. El desacuerdo es resultado de que algunos enunciados no se pueden refutar alegando hechos en contra, sencillamente porque esos enunciados no son aserciones, pues no proporcionan información sobre los fenómenos de la realidad del mundo ${ }^{50}$. Que este es también el caso ante el que nos hallamos queda demostrado, a mi modo de ver, desde que nos imaginamos a Kelsen y Lenin enredados en una discusión sobre la verdadera "esencia" de la democracia. Sus argumentos serían mutuamente irrefutables en base a hechos. Por un lado, para Lenin no hay duda de que el proletariado representa la gran mayoría del pueblo, mientras que, por otro lado, como Kelsen señaló en alguna ocasión, si el proletariado no ha sido capaz de obtener el poder por cauces democráticos es sencillamente porque la suposición de Marx y Engels de que el proletariado es la clase mayoritaria numéricamente hablando es falsa, puesto que, si fuera verdadera, nada le habría impedido, en un sistema de democracia representativa y liberal, obtener y ejercer el poder a través de los partidos políticos que lo

\footnotetext{
49 Ibid., pp. 69 y ss.
}

${ }^{50}$ Ibid., p. 70 
representan ${ }^{51}$. De esta manera, un intercambio dialéctico de argumentos y contraargumentos sobre si el proletariado es o no la clase mayoritaria en número, solo tendría el efecto de reafirmar a los contendientes en sus posiciones. Parece que solo cabe esperar un diálogo de sordos. Esta apreciación se ve reforzada, si Carrió tiene razón, porque la forma como perciben los adversarios -Kelsen y Lenin- el fenómeno se apoya en consideraciones meramente subjetivas sobre la realidad de los hechos. Da la impresión de que por esta vía no cabe esperar un entendimiento.

3. Por último, hay todavía un punto de disputa que afecta a Kelsen y Voegelin, y da lugar a un tercer tipo de controversias al que Carrió se refiere como "disputas sobre clasificaciones". Estos desencuentros son resultado de un exceso de confianza en ciertas clasificaciones, que se piensa que son la verdadera forma de agrupar los fenómenos, en lugar de verlas como instrumentos que facilitan su comprensión ${ }^{52}$. El error es creer que los fenómenos deben acomodarse a las clasificaciones, y no a la inversa. Kelsen opina que la dicotomía de Voegelin entre una representación "elemental" y una representación "existencial", en los términos en que es expuesta, no es admisible, pues para él solo se puede aceptar como genuina representación una democrática. Asumir que el gobierno soviético representa al pueblo soviético en sentido existencial, por el hecho de que este obedece las disposiciones gubernamentales de aquel, bajo la amenaza de la gigantesca maquinaria militar que es capaz de operar, solo puede ser resultado de una adulteración malintencionada del concepto de representación política, que estaría motivada por algún interés misterioso que parece guiar a Voegelin. Ciertamente, como bien indica Carrió, las clasificaciones, por artificiosas que puedan parecer, no se valoran por ser verdaderas o falsas, sino porque tienen utilidad o carecen de ella ${ }^{53}$, en la medida en que facilitan la comprensión de los fenómenos. Este sería su único criterio de corrección.

\footnotetext{
${ }_{51}$ Véase Kelsen, H., Socialismo y estado: una investigación sobre la teoría política del marxismo, Madrid, Edersa, 1985, pp. 75-76; "La teoría política del bolchevismo. Un análisis crítico", op. cit., p. 186; "La teoría política del socialismo", Escritos sobre la democracia y el socialismo, Madrid, Debate, 1988, p. 72.

52 Carrió, G., Notas sobre derecho y lenguaje, op. cit., p. 72.

${ }^{53}$ Ídem.
} 


\section{ReFERENCIAS Bibliográficas}

Carrió, G., Notas sobre derecho y lenguaje, Buenos Aires, Abeledo-Perrot, 1973.

García Amado, J. A., Hans Kelsen y la norma fundamental, Madrid, Marcial Pons, 1996.

Guiboug, R.; Ghigliani, A.; Guarinoni, R., Introducción al conocimiento juridico, Buenos Aires, Astrea, 1973.

Kelsen, H., Allgemeine Staatslehre, Berlin, Julius Springer, 1925.

- Esencia y valor de la democracia, Oviedo, KRK Editores, 2006.

- "Los fundamentos de la democracia", Escritos sobre la democracia y el socialismo, Madrid, Debate, 1988.

- ¿Una nueva ciencia de la politica? Réplica a Eric Voegelin, Buenos Aires, Katz Editores, 2006.

- "El problema del parlamentarismo", Escritos sobre la democracia y el socialismo, Madrid, Debate, 1988.

- Socialismo y estado: una investigación sobre la teoría politica del marxismo, Madrid, Edersa, 1985.

— "La teoría política del bolchevismo. Un análisis crítico", Escritos sobre la democracia y el socialismo, Madrid, Debate, 1988.

- "La teoría política del socialismo", Escritos sobre la democracia y el socialismo, Madrid, Debate, 1988.

— "Verteidigung der Demokratie", Verteidigung der Demokratie, Tübingen, Mohr Siebeck, 2006.

- "Vom Wesen und Wert der Demokratie" (1. Auflage), Verteidigung der Demokratie, Tübingen, Mohr Siebeck, 2006.

- "Zur Soziologie der Demokratie", Die Wiener Rechtstheoretische Schule. Schriften von Hans Kelsen, Adolf Merkl, Alfred Verdross, 2, Wien, Europa Verlag, 1968.

Lagi, S., El pensamiento político de Hans Kelsen (1911-1920). Los orígenes de "De la esencia y valor de la democracia", Madrid, Biblioteca Nueva, 2007.

Pintore, A., "Democracia sin derechos. En torno al Kelsen democrático", DOXA, 23, 2000. 
Rodilla, M. A., Teoría del Derecho, Salamanca, Ratio Legis, 2013.

Sendín, J. A., La filosofía moral de Hans Kelsen, Madrid, Marcial Pons, 2017.

Stevenson, Ch., Ethics and Language, New Haven and London, Yale University Press, 1944.

- "Persuasive Definitions", Facts and Values. Studies in Ethical Analysis, Westport (Connecticut), Greenwood Press, 1975.

Voegelin, E., La nueva ciencia de la política. Una introducción, Buenos Aires, Katz Editores, 2006.

DOI: http://doi.org/10.15366/bp2019.20.007

Bajo Palabra. II Época. No20. Pgs: 125-142 